\title{
Electron beam ablation of materials
}

S. D. Kovaleski, ${ }^{\text {a) }}$ R. M. Gilgenbach, ${ }^{\text {b) }}$ L. K. Ang, and Y. Y. Lau

Intense Energy Beam Interaction Laboratory, Department of Nuclear Engineering and Radiological Sciences, University of Michigan, Ann Arbor, Michigan 48109-2104

(Received 21 June 1999; accepted for publication 3 September 1999)

\begin{abstract}
The channelspark, a low accelerating voltage, high current electron beam accelerator, has been used for ablation of materials applied to thin film deposition. The channelspark operates at accelerating voltages of 10 to $20 \mathrm{kV}$ with $\sim 1500 \mathrm{~A}$ beam currents. The electron beam ionizes a low-pressure gas fill (10-20 mTorr Ar or $\mathrm{N}_{2}$ ) to compensate its own space charge, allowing ion focused transport. Ablation of $\mathrm{TiN}, \mathrm{Si}$, and fused silica has been studied through several plasma diagnostics. In addition, thin films of $\mathrm{SiO}_{2}$ have been deposited and analyzed. Strong optical emission from ionized species, persisting for several microseconds, was observed in the electron beam ablated plumes. Free electron temperatures were inferred from relative emission intensities to be between 1.1 and 1.2 eV. Dye-laser-resonance-absorption photography showed Si atom plume expansion velocities from 0.38 to $1.4 \mathrm{~cm} / \mu$ s for several pressures of Ar or $\mathrm{N}_{2}$ background gas. A complex, multilobed plume structure was also observed, yielding strong indications that an electron beam instability is occurring, which is dependent upon the conductivity of the target. Nonresonant interferometry yielded line-averaged electron densities from 1.6 to $3.7 \times 10^{23} \mathrm{~m}^{-3}$ near the target surface. Resonant UV interferometry performed on Si neutral atoms generated in the ablation plumes of fused silica targets measured line integrated densities of up to $1.6 \times 10^{16} \mathrm{~cm}^{-2}$, with the total number of ablated silicon neutrals calculated to be in the range $2.0 \times 10^{15}$ to $5.0 \times 10^{13}$. Electron beam deposited films of fused silica were microscopically rough, with a thickness variation of $7 \%$. The average $\mathrm{SiO}_{2}$ deposition rate was found to be about $0.66 \mathrm{~nm} / \mathrm{shot}$. The electron beam-deposited fused silica films had accurately maintained stoichiometry. Ablated particulate had an average diameter near $60 \mathrm{~nm}$, with a most probable diameter between 40 and $60 \mathrm{~nm}$. For $\mathrm{SiO}_{2}$ targets, the mass of material ablated in the form of particulate made up only a few percent of the deposited film mass, the remainder being composed of atomized and ionized material. (c) 1999 American Institute of Physics. [S0021-8979(99)01324-9]
\end{abstract}

\section{INTRODUCTION}

Laser ablation of materials for thin film deposition, known as pulsed laser deposition (PLD) is the most extensively studied ablative deposition concept. Laser ablation plumes have been studied by quadrupole mass spectroscopy, ${ }^{1}$ by spectroscopy, ${ }^{2,3}$ and by resonant laser diagnostics. ${ }^{4,5}$ Materials such as iron, ${ }^{4,6,7}$ titanium, ${ }^{2}$ titanium nitride, ${ }^{8}$ and silicon ${ }^{1}$ have all been ablated by or produced during laser ablation. Fused silica has been ablated by ultrafast lasers, ${ }^{9}$ by excimer lasers, ${ }^{10}$ and by vacuum ultraviolet (VUV) preirradiation. ${ }^{11} \mathrm{SiO}_{2}$ has even been deposited by $\mathrm{Si}$ ablation in radio-frequency (rf) oxygen plasmas. ${ }^{12}$ Laser ablation has been coupled with electron beam irradiation ${ }^{13}$ and ion beam irradiation ${ }^{14}$ as well.

With the advent of pseudosparks, ${ }^{15}$ low energy, high current electron beams have been studied as energy beams for materials processing. A $20 \mathrm{kV}, 0.1-1 \mathrm{kA}$ pseudospark was used to drill $300-\mu \mathrm{m}$-diam holes in $\mathrm{Al}$ and to ablate $\mathrm{YBa}_{2} \mathrm{Cu}_{3} \mathrm{O}_{7-x} \cdot{ }^{16} \mathrm{~A} 20 \mathrm{kV}, 400 \mathrm{~A}$ pseudospark was used to deposit thin films of $\mathrm{Cu}$ on glass by ablative deposition. ${ }^{17} \mathrm{~A}$ $14 \mathrm{kV}$ pseudospark was used to deposit $\mathrm{YBa}_{2} \mathrm{Cu}_{3} \mathrm{O}_{7-x}$ on $\mathrm{SrTiO}_{3} .{ }^{18}$ Eventually, the channelspark was introduced, which is a pseudospark-like device with the usual multiple,

\footnotetext{
a)Permanent address: GE Lighting, 1975 Noble Rd, Bldg. 335C., Nela Park, Cleveland, OH 44112-6300.

${ }^{b}$ Electronic mail: rongilg@engin.umich.edu
}

hollow electrodes between anode and cathode replaced by a long, continuous dielectric tube. ${ }^{19}$ The channelspark was developed for thin film deposition applications. The first films reported deposited by channelspark electron beam ablation were $\mathrm{YBa}_{2} \mathrm{Cu}_{3} \mathrm{O}_{7-x}$ on $\mathrm{SrTiO}_{3} .{ }^{20}$ Witke ${ }^{21}$ compared channelspark electron beam ablation of $\mathrm{Al}$ to yttriumaluminum-garnet (YAG) laser ablation and Kovaleski ${ }^{22}$ compared channelspark electron beam ablation of Fe to excimer laser ablation. The plume dynamics of channelspark electron beam ablated fused silica have also been imaged. ${ }^{23}$

This article presents a summary of experiments to characterize the plumes of electron beam ablative deposition. Free electron temperatures of electron beam ablated plumes have been measured through optical emission spectroscopy. Dye laser resonance absorption photography (DLRAP) measurements have yielded plume front expansion velocities for ablation of fused silica and silicon. DLRAP has also provided evidence of a suspected electron beam instability at work during electron beam ablation. Electron densities have been measured by nonresonant interferometry. Lineintegrated densities of near-ground state neutral $\mathrm{Si}$ atom plumes have been measured by resonant ultraviolet interferometry and related to the total population of neutral and singly ionized $\mathrm{Si}$. Thin films of fused silica have been deposited and analyzed. Electron beam ablated particulate has been studied through deposition as well. 


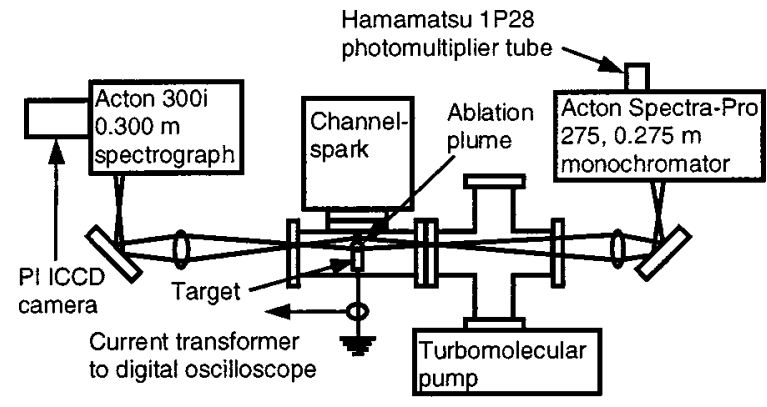

FIG. 1. Diagram of the combined time integrated and time resolved optical emission spectroscopy experimental configuration for electron beam ablation.

\section{EXPERIMENTAL CONFIGURATION}

The ablation-driving electron beam source used for these experiments was a channelspark, developed at $\mathrm{KfK}$ in Germany. ${ }^{19}$ The channelspark has the following parameters: negative $10-20 \mathrm{kV}$ charging potential, $1500 \mathrm{~A}$ beam current, 10-20 mTorr of background gas pressure for ion focusing (either Ar or $\mathrm{N}_{2}$ for this experiment), pulse energy of about 1 $\mathrm{J}$, incident fluence less than $30 \mathrm{~J} / \mathrm{cm}^{2}$, spot size $0.013 \mathrm{~cm}^{2}$, and pulse length of $200 \mathrm{~ns}$. The authors have installed an air-filled, pressurized, triggered spark-gap switch for command triggering the channelspark. Electron beam ablation experiments took place in a turbomolecular pump evacuated, stainless steel vacuum cross. The channelspark electron beam travels through a dielectric tube to a target within the vacuum cross whose surface normal is canted $45^{\circ}$ from the electron beam axis. The ablation plume expands along the target surface normal. Note that for insulating targets the return current must flow through the e-beam produced Ar or $\mathrm{N}_{2}$ plasma.

Optical emission spectroscopy was either wavelength resolved, time integrated, or time-resolved, single wavelength. The combined optical emission diagnostic is shown in Fig. 1. Wavelength resolved optical emission spectroscopy was performed with a $0.300 \mathrm{~m}$ Acton 300i imaging spectrograph with an attached (Princeton Instruments ICCD-576/RB-EM) intensified, gated charge-coupled device (CCD) detector $(576 \times 384$ pixels $)$. The spectrograph utilized a 2400 lines $/ \mathrm{mm}$ grating blazed at $240 \mathrm{~nm}$. The camera was operated in an externally gated mode with a (PI PG-200) programmable pulse generator for gates and delays on nanosecond time scales. The channelspark plume was imaged on the slit of the spectrograph with a fused silica lens of $f=360$ $\mathrm{mm}$. A $20 \mu \mathrm{m}$ slit was used. Due to the necessity of angling the target in e-beam ablation, the slit was positioned $45^{\circ}$ relative to the target surface (parallel to the e beam) and crossing the surface such that the center of the slit was about $1 \mathrm{~mm}$ from the beam impact point. An UV-enhanced, Al first-surface turning mirror was also necessary in the imaging setup due to space constraints.

Time resolved optical emission spectroscopy was performed with a $0.275 \mathrm{~m}$ (Acton SpectraPro 275) monochromator with a (Hamamatsu 1P28) photomultiplier tube for measurement of the optical signal. The monochromator utilized a 1200 lines $/ \mathrm{mm}$ grating blazed at $500 \mathrm{~nm}$. The photo- multiplier tube signal was recorded on a (Tektronix TDS 220) digitizing oscilloscope. The channelspark plume was imaged on the slit of the monochromator with a fused silica lens of $f=250 \mathrm{~mm}$. A $100 \mu \mathrm{m}$ slit was used for the entrance and exit of the monochromator. Imaging of the plume on the slit was the same as described in the preceding paragraph. An UV-enhanced, Al first-surface turning mirror was also necessary in the imaging setup due to space constraints.

Dye-laser-resonance-absorption photography (DLRAP) is a species resolving, imaging diagnostic. An experimental diagram of DLRAP performed on electron beam ablation plumes was given in a previous article. ${ }^{23}$ DLRAP was performed using a dye laser pumped by a $\mathrm{XeCl}$ excimer laser. The dye laser has a pulse length of $20 \mathrm{~ns}$, and a linewidth of $0.2 \mathrm{~cm}^{-1}$. DLRAP experiments were performed during electron beam ablation of silicon or fused silica targets. Frequency doubled laser light (from Coumarin 153 dye) was absorbed by the near-ground state, neutral $\mathrm{Si} 3 p^{2}{ }^{1} D$ $-4 s^{1} P^{0}$ transition at $288.1579 \mathrm{~nm}$ of the ablated $\mathrm{Si}$ atom plumes. The dye laser beam was expanded and recollimated through a telescope and passed perpendicular to the ablation plume and electron beam. The DLRAP camera was setup in an open shutter arrangement; a lens focuses the diagnostic beam through an adjustable iris, to reduce plasma light from the ablation event, and images the absorption on high-speed photographic film (Polaroid type 667). Photographs have been scanned into a personal computer for adjustment of contrast and background subtraction. A digital delay generator controls the relative delay between the channelspark electron beam and the dye laser pulse.

Interferometry is a powerful diagnostic that can measure the absolute density of electrons, in the case of nonresonant interferometry, or can measure the density of atoms or ions, in the case of resonant ultraviolet interferometry. For both types of interferometry, a dye laser beam is expanded, collimated, and split into the two legs of a Mach-Zehnder interferometer. When the two beams are recombined, with a slight angular separation, straight interference fringes are produced. If a plume is produced in one of the legs of the interferometer, its index of refraction will advance or retard the phase of the beam in that leg, resulting in a shift of the interference fringes. The index of refraction due to the dispersion of an electromagnetic wave in an unmagnetized plasma allows measurement of the electron density. The increased index of refraction near a resonant transition allows measurement of the atomic or ionic species responsible for the resonance. The experimental details and theory of interferometry as applied to ablation plumes have been given in previous articles. ${ }^{4,5}$

\section{EXPERIMENTAL RESULTS:}

\section{A. Optical emission spectroscopy}

Preliminary results of optical emission spectroscopy on channelspark electron beam ablation experiments have been reported in previous publications. ${ }^{22,24}$ This article presents detailed analysis of both time-integrated, wavelengthresolved spectroscopy as well as time-resolved, singlewavelength spectroscopy, which have been applied to elec- 


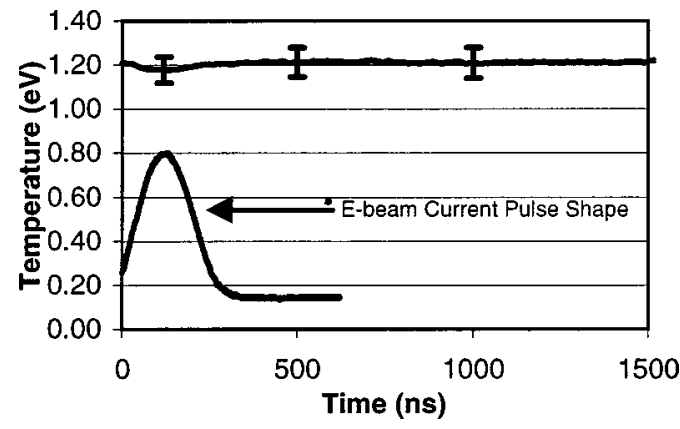

FIG. 2. Plot of the free electron temperature vs time obtained from the observed relative intensity of transitions from two subsequent ionization states. The intensity of the Si II transition at $505.598 \mathrm{~nm}$ is ratioed to the intensity of the Si I transition at $288.1579 \mathrm{~nm}$. Sample error bars represent + and - one standard deviation. An electron beam current pulse is also plotted for time reference.

tron beam ablation plumes. In the case of electron beam ablation of fused silica, bright emission from neutral $\mathrm{Si}$, singly ionized $\mathrm{Si}$, and doubly ionized $\mathrm{Si}$ has been observed in the ablated plumes. Emission from the ${ }^{1} D-{ }^{1} P^{O}$ Si I transition at $288.1579 \mathrm{~nm}$ and from the ${ }^{2} P^{O}-{ }^{2} D \mathrm{Si}$ II transition at $505.598 \mathrm{~nm}$ have been observed to rise sharply during the electron beam current pulse and to then decay slowly for 4 $\mu$ s. Even emission from the ${ }^{3} S-{ }^{3} P^{O}$ Si III transition at $456.782 \mathrm{~nm}$ has been found to persist for $2 \mu \mathrm{s}$. These times, as well as all other times measured in this article, were measured relative to the leading edge of the electron beam current pulse. The leading edge is defined as the time at which the electron beam current pulse has initially risen to $10 \%$ of its maximum value, which will be referred to as $\tau_{10}$ for the remainder of this article.

Time resolved emission intensities from the ${ }^{1} D-{ }^{1} P^{O}$ $\mathrm{Si}$ I transition at $288.1579 \mathrm{~nm}$ and the ${ }^{2} P^{O}{ }_{-}^{2} D$ Si II transition at $505.598 \mathrm{~nm}$ were used in conjunction with the Saha equation to determine a free electron temperature through time following the channelspark electron beam current pulse. The Saha equation, in a modified form relating the temperature to the intensity of emission from two subsequent ionization states, ${ }^{25}$ is

$$
\begin{aligned}
\frac{i_{i+1}}{i_{i}}= & \frac{A_{i+1} g_{i+1} \lambda_{i}}{\sqrt{\pi} A_{i} g_{i} \lambda_{i+1}}\left(4 \pi a_{O}^{3} N_{e}\right)^{-1}\left(\frac{k T}{E_{H}}\right)^{3 / 2} \\
& \times \exp \left(-\frac{E_{i+1}+E_{\infty}-E_{i}-\Delta E_{\infty}}{k T}\right),
\end{aligned}
$$

where the subscript $e$ denotes the electrons, $i$ denotes the lower ionization state, $i+1$ denotes the next ionization state, $N$ is a density, $a_{o}$ is the Bohr radius, $E_{H}$ is the Rydberg energy, $E_{\infty}$ is the ionization energy of the lower state, $\Delta E_{\infty}$ is a correction to the ionization energy, and $k T$ is the electron temperature. The Einstein spontaneous emission coefficient is given by $A, g$ is the statistical weight, and $\lambda$ is the emission wavelength. Experimentally measured free electron temperatures are presented in Fig. 2; a scaled electron beam current pulse is also plotted in Fig. 2 as a time reference. The calculated free electron temperature appears to fall during the electron beam current pulse (the bound electron population distribution is non-Maxwellian during the current pulse), and then rises to about $1.2 \mathrm{eV}$ after the current pulse. The electron temperature remains at $1.2 \mathrm{eV}$ until the intensity of the optical emission has fallen such that the temperature can no longer be accurately measured. As will be shown, only the free electron temperatures calculated by this method after the electron beam pulse has ended are valid.

As mentioned in the preceding paragraph, the apparent temperature in Fig. 2 drops during the electron beam current pulse. The real free electron temperature does not in fact drop. Since the fast beam electrons are enhancing the population of excited and ionized states during the electron beam pulse, the calculation of free electron temperature from the relative emission intensity of subsequent ionization states is impossible. Jayakumar postulated, and Brake experimentally observed $^{26,27}$ that fast particles affect the populations of high lying energy states more than low lying states. This effect enhances the ionization and excitation of Si II relative to Si I, causing the calculated temperature to drop with the emission intensity ratio. After the electron beam current has fallen to zero, the atomic and ionic populations quickly return to equilibrium, allowing partial local thermodynamic equilibrium to be established, and free electron temperatures to be calculated from relative emission intensities.

The free electron density (line-averaged) used for these calculations, $1.7 \times 10^{23} \mathrm{~m}^{-3}$, was determined by nonresonant interferometry, which is presented later in this article. Since the electron beam current pulse has nearly fallen to zero $300 \mathrm{~ns}$ after $\tau_{10}$, electron densities measured at this time were used for the calculation. At times after the electron beam current has fallen to zero, the effects of fast particles on the relative populations of the ionization and excitation states of the plume species should have decayed away. Also, the electron density is constantly decaying due to plume expansion, so the latest time data on electron density provides the best estimate for the electron density for the times of interest. It should also be noted here that the electron densities observed during channelspark electron beam ablation are adequate to establish partial local thermal equilibrium (LTE). Partial LTE is valid for transitions originating in energy levels with principal quantum numbers larger than 3 and for species ionized up to two times.

In addition to studying the optical emission of fused silica electron beam ablation plumes, the emission from e-beam ablation plumes of TiN were studied. These optical emission spectra are also presented, but not analyzed, in a previous article ${ }^{24}$ and are characterized by intense emission from singly ionized titanium. This intense Ti II emission was used to construct an atomic Boltzmann plot to calculate the free electron temperature. In this well-known method, optical emission data are plotted according to the equation

$$
\ln \left(\frac{i_{n m} \lambda_{m n}}{g_{m} A_{m n}}\right)=\left(\frac{-E_{m}}{k T}\right)+\ln \left(\frac{\hbar c l N}{2 Z_{a}(T)}\right)
$$

where the subscript $n$ denotes the lower state, $m$ denotes the upper state, $i_{n m}$ is the emission intensity, $\lambda_{m n}$ is the emission frequency, $A_{m n}$ is the Einstein spontaneous emission coefficient, $g_{m}$ is the statistical weight of level m, $E_{m}$ is the energy of state $\mathrm{m}, k T$ is the electronic temperature, $N$ is the total 
TABLE I. Table of the spectroscopic data used in an atomic Boltzmann plot to determine the free electron temperature in plumes from TiN ablation targets. All values correspond to optical emission lines of Ti II.

\begin{tabular}{crccc}
\hline \hline Wavelength $(\mathrm{nm})$ & $g_{m}$ & $A_{m n}\left(\times 10^{8} \mathrm{~s}^{-1}\right)$ & Intensity (arb. units) & $E_{m}(\mathrm{eV})$ \\
\hline 323.451 & 10 & 1.38 & 1.031 & 3.88 \\
323.658 & 8 & 1.11 & 0.7895 & 3.86 \\
323.904 & 6 & 0.986 & 0.6128 & 3.84 \\
324.199 & 4 & 1.16 & 0.4774 & 3.82 \\
321.707 & 10 & 0.169 & 0.2890 & 3.88 \\
319.091 & 8 & 1.30 & 0.4032 & 4.97 \\
320.256 & 6 & 1.10 & 0.2820 & 4.95 \\
322.284 & 8 & 0.260 & 0.2647 & 3.86 \\
\hline \hline
\end{tabular}

species density, $Z_{a}(T)$ is the partition function at temperature $T$, and $l$ is the path length. If the intensities of several lines are known, a least squares fit of the left-hand side of Eq. (2) can be performed versus the energy of the upper states, $E_{m}$. The inverse of the slope of such a fit yields the electronic temperature. If LTE or partial LTE can be established, as it has been for these experiments, the electronic temperature represents the free electron temperature. The constant term of Eq. (2) is generally also determined by the fit so that fitting eliminates any correction or calibration factors.

A time-integrated spectrum was chosen, which was collected during e-beam ablation of TiN, over a 100 ns gate centered $260 \mathrm{~ns}$ following $\tau_{10}$. For this ablation event, the channelspark was charged to $16.5 \mathrm{kV}$ and the electron beam current was measured to be $1700 \mathrm{~A}$ at the target. The ablation was conducted in a 12 mTorr background of Ar. The optical emission was observed for wavelengths ranging from 319 to $326 \mathrm{~nm}$. Several Ti II lines are present in this portion of the spectrum, with a minimum of interfering Ar emission lines. Table I lists the Ti II lines observed and used for construction of the atomic Boltzmann plot, along with their relevant published spectroscopic data. ${ }^{28}$ A least squares fit to the data in Table I, following Eq. (2), yielded a free electron temperature of $1.1 \mathrm{eV}$. Partial local thermodynamic equilibrium was determined, as discussed earlier, allowing this temperature to be equated with the free electron temperature.

Analysis and Discussion. The $1.2 \mathrm{eV}$ electron temperature measured during fused silica ablation is very close to the $1.1 \mathrm{eV}$ arrived at independently from the optical emission of TiN ablation plumes. Table II lists electron temperatures measured by other authors for laser and electron beam ablation of several other materials. Comparison of the electron temperatures presented here with those in Table II shows that free electron temperatures from electron beam ablation would appear to be quite comparable to those of high-fluence laser ablation plumes early in time. Also, it appears that laser ablation plasmas reach higher temperatures during and at early times compared to the beam pulse than channelspark ablation plasmas, but channelspark plasmas maintain a higher free electron temperature during plume expansion at times well after the pulse.

\section{B. Dye laser resonance absorption photography}

Summary of experimental results and discussion. A previous article gave experimental details and preliminary results of DLRAP applied to Si atom plumes generated by

TABLE II. Comparison of electron temperatures, electron densities, and neutral atom and ion line-integrated densities measured in this work with measurements published by other authors.

\begin{tabular}{|c|c|c|c|c|c|}
\hline $\begin{array}{l}\text { Ablation } \\
\text { source }\end{array}$ & Target & $\begin{array}{l}\text { Electron } \\
\text { temperature } \\
(\mathrm{eV})\end{array}$ & $\begin{array}{l}\text { Electron } \\
\text { density } \\
\left(\mathrm{m}^{-3}\right)\end{array}$ & Line-integrated density $\left(\mathrm{cm}^{2}\right)$ & Ref. \\
\hline Channelspark & $\mathrm{SiO}_{2}$ & $1.1-1.2$ & $1.6-3.7 \times 10^{23}$ & $1 \times 10^{15}-1.6 \times 10^{16}$ & $\begin{array}{l}\text { This } \\
\text { work }\end{array}$ \\
\hline Channelspark & $\mathrm{Al}$ & 1.3 & $\cdots$ & $\cdots$ & 21 \\
\hline $\begin{array}{l}\mathrm{KrF} \text { excimer } \\
\text { laser }\end{array}$ & $\mathrm{Fe}$ & $0.2-0.8$ & $\cdots$ & 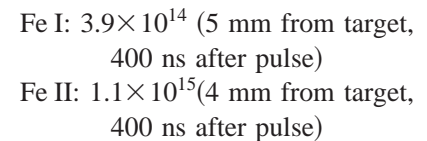 & 4 \\
\hline $\begin{array}{l}\mathrm{XeCl} \text { excimer } \\
\text { laser }\end{array}$ & $\mathrm{Ti}$ & $2-0.6$ & $\begin{array}{l}1 \times 10^{24}- \\
1 \times 10^{22}\end{array}$ & . & 29 \\
\hline Nd:YAG & $\begin{array}{c}\mathrm{Ti} \\
\text { alloy }\end{array}$ & $3.8-0.66$ & $2.5 \times 10^{23}$ & $\cdots$ & 3 \\
\hline $\begin{array}{l}\text { KrF excimer } \\
\text { laser }\end{array}$ & $\begin{array}{l}\mathrm{Al} \text { and } \\
\mathrm{Al}_{2} \mathrm{O}_{3}\end{array}$ & $\cdots$ & $\begin{array}{l}1.2 \times 10^{24} \\
-3 \times 10^{23}\end{array}$ & $\cdots$ & 30 \\
\hline $\begin{array}{l}\mathrm{KrF} \text { excimer } \\
\text { laser }\end{array}$ & $\mathrm{Mg}$ & $\cdots$ & $4-1 \times 10^{24}$ & 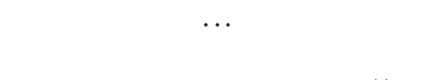 & 31 \\
\hline $\begin{array}{l}\text { KrF excimer } \\
\text { laser }\end{array}$ & Al & $\cdots$ & $\cdots$ & $\begin{array}{l}\text { Al ground state neutrals: } 3 \times 10^{14}(2 \\
\text { mm from target, } 290 \mathrm{~ns} \text { after } \\
\text { pulse) to } 5 \times 10^{14}(5 \mathrm{~mm} \text { from } \\
\text { target, } 500 \mathrm{~ns} \text { after pulse })\end{array}$ & 5 \\
\hline $\begin{array}{l}\mathrm{KrF} \text { excimer } \\
\text { laser }\end{array}$ & $\mathrm{Mg}$ & $\cdots$ & $\cdots$ & $\begin{array}{c}\text { Mg I: } 1 \times 10^{15}(1 \mathrm{~mm} \text { from target, } 1 \\
\mu \mathrm{s} \text { after pulse }) \\
\text { Mg II: } 1 \times 10^{13}(1 \mathrm{~mm} \text { from target, } \\
1 \mu \text { s after pulse })\end{array}$ & 32 \\
\hline
\end{tabular}



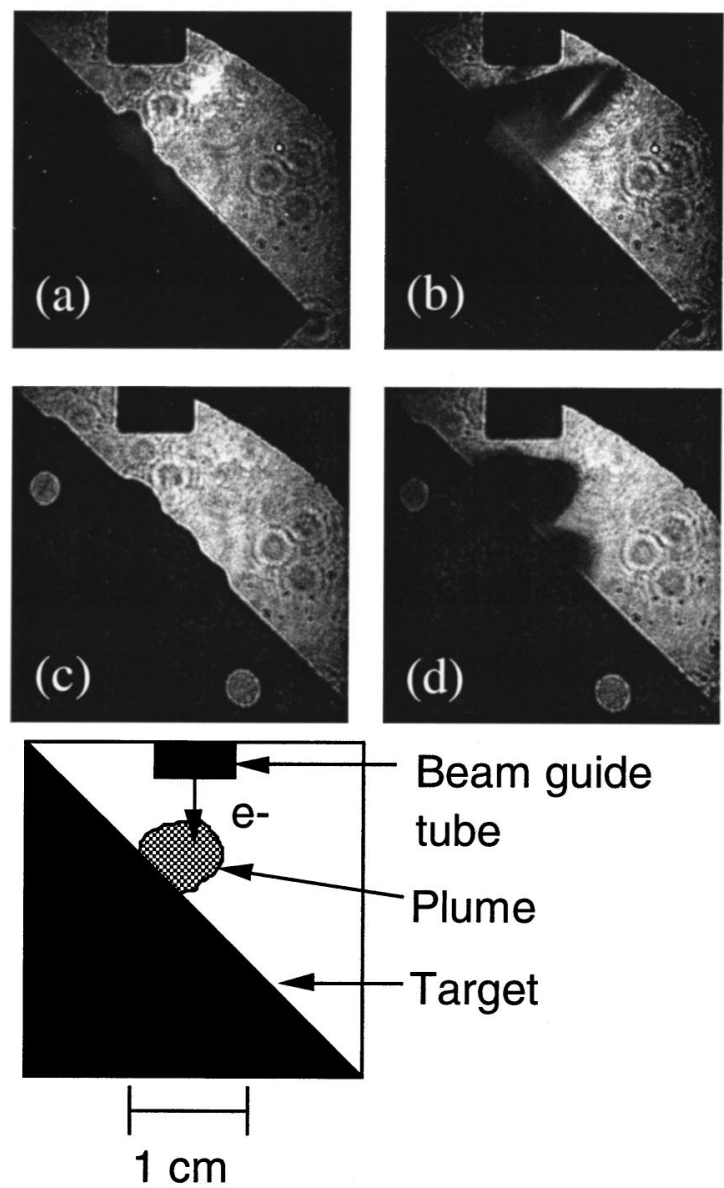

FIG. 3. Dye laser resonance absorption photographs of the ablation of silicon dioxide and pure silicon. The dye laser is tuned to the center of the Si I near ground state line at $288.158 \mathrm{~nm}$. Parts (a) and (b) are DLRAP photographs taken during the ablation of fused silica in a background gas fill of 20 mTorr of $\mathrm{N}_{2}$. Parts (c) and (d) are DLRAP photographs taken during the ablation of silicon in a background gas fill of 10 mTorr of Ar. (a) A DLRAP photograph taken $200 \mathrm{~ns}$ after the beginning of the electron beam current pulse during the ablation of fused silica. (b) A DLRAP photograph taken $1420 \mathrm{~ns}$ after the beginning of the electron beam current pulse during the ablation of fused silica. (c) A DLRAP photograph taken $220 \mathrm{~ns}$ after the beginning of the electron beam current pulse during the ablation of silicon. (d) A DLRAP photograph taken $1380 \mathrm{~ns}$ after the beginning of the electron beam current pulse during the ablation of silicon. Times are measured from the leading edge of the current measured at the target to the leading edge of the dye laser pulse measured by a PIN diode. Also included is a schematic showing the various features of the picture, including the scale length.

electron beam ablation of fused silica. ${ }^{23}$ Presented here are summaries of the results of DLRAP applied to electron beam ablation of both silicon and fused silica.

Several DLRAP images of electron beam ablation plumes are presented in Fig. 3. These images were taken during electron beam ablation of an electrically insulating material, fused silica, and an electrically (semi-) conducting material, silicon. For both sets of images, the dye laser backlighter was tuned to probe the ${ }^{1} D-{ }^{1} P^{O} \mathrm{Si}$ I transition at $288.1579 \mathrm{~nm}$. This transition represents a near ground state atomic transition that, at a $1.2 \mathrm{eV}$ free electron temperature, accounts for $1 / 5$ of the total population of Si neutrals in the ablation plumes.

Examining the DLRAP images of Si neutral plumes generated by electron beam ablation of fused silica and silicon, a complex plume structure is observed. For electron beam ablation of the electrically insulating, fused silica target, at 200 ns following $\tau_{10}$, a plume consisting of two lobes is observed [Fig. 3(a)]. It should be stated that the time at which this image was taken, $200 \mathrm{~ns}$, falls during the electron beam pulse. At late times, $1420 \mathrm{~ns}$ after $\tau_{10}$, the multiple lobes have coalesced into a single plume [Fig. 3(b)]. The multiplicity of plumes is much more pronounced for the case of an electrically conducting target, silicon. As shown in Fig. 3(c), at $220 \mathrm{~ns}$ following $\tau_{10}$, three separate and distinct plumes are found, spread more extensively across the target than in the case of fused silica ablation. The image taken $1380 \mathrm{~ns}$ following the leading edge of the e-beam current pulse [Fig. $3(d)]$ shows that the plumes do not coalesce into a single plume, even at late times.

An electron beam instability is speculated to be the cause of the multiple plumes found in these DLRAP images. The instability apparently occurs when the channelspark electron beam interacts with a target. Given that the multiplicity of plumes is much more pronounced for the electrically conducting silicon target compared to that for the insulating fused silica target, the instability is likely dependent upon the target conductivity or surface currents. A target that had sustained damage from 3000 electron beam pulses was examined under an optical microscope. Multiple damage sites were observed, but it was impossible to ascertain whether the multiple impacts were caused during a single, unstable electron beam pulse or during multiple electron beam pulses. Others ${ }^{21}$ have previously reported what appeared to be optical emission from separate sites on aluminum targets.

Time scans of DLRAP images, similar to the images in Fig. 3, were taken during electron beam ablation of both silicon targets and fused silica targets, on the resonant Si I transition at $288.1579 \mathrm{~nm}$. The DLRAP time scans were performed during the ablation of each target in background gas fills of either $\mathrm{Ar}$ or $\mathrm{N}_{2}$. The background fill pressures ranged from 10 to 20 mTorr for either gas. In the case of fused silica ablation in $\mathrm{N}_{2}$ background, the channelspark charging voltage, as well as pressure, was varied. The position of the plume front (the leading edge of the absorption shadow) relative to the surface of the target, along the target normal, was measured at each time of the scan. Times were measured relative to the leading edge of the electron beam current pulse. Figure 4 shows plots of the neutral Si plume front position versus time for electron beam ablation of fused silica at several pressures of $\mathrm{Ar}$ or $\mathrm{N}_{2}$. Figure 5 shows the same type of plots for electron beam ablation of silicon at several pressures of $\mathrm{Ar}$ or $\mathrm{N}_{2}$.

The plume front position in Figs. 4 and 5 increases initially, and then levels off later in time. The apparent slowing of the plume expansion occurs because the plume density has diminished such that it is no longer detectable. Least squares fits were performed on the initial plume front data to determine an expansion velocity. During the electron beam ablation of fused silica in an Ar background, shown in Fig. 4(a), the plume expansion velocity ranges between 0.59 and 1.4 $\mathrm{cm} / \mu \mathrm{s}$. During ablation of fused silica in an $\mathrm{N}_{2}$ background, not only the background gas pressure, but also the channel- 

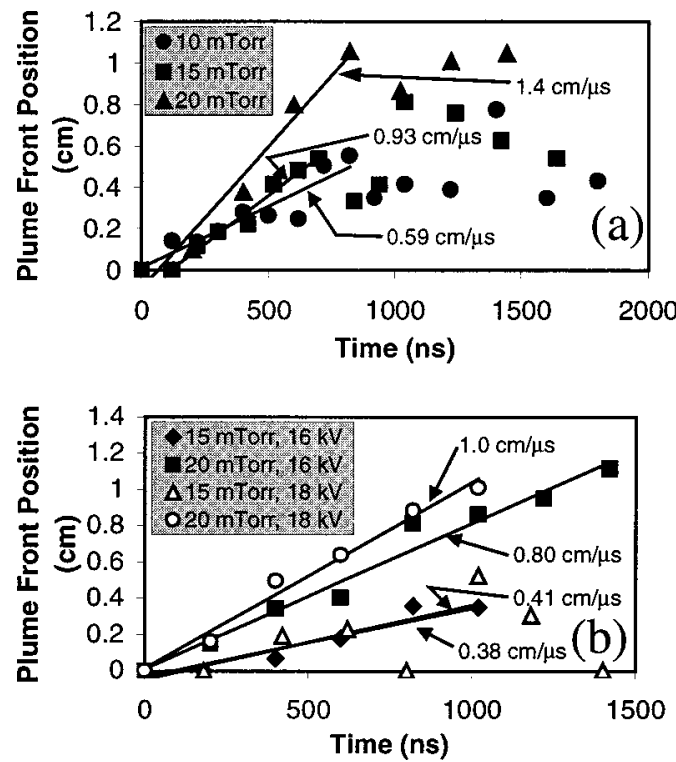

FIG. 4. Plot of Si I near-ground-state plume front position vs time following the electron beam pulse in an $\mathrm{Ar}$ or $\mathrm{N}_{2}$ background at various pressures. Data taken from DLRAP photographs of channelspark ablation of fused silica. The dye laser was tuned to the center of the Si I transition at 288.1579 $\mathrm{nm}$. The initial time plume front data were fit by the method of least squares to determine an expansion velocity. The fit lines are also plotted along with their slopes. (a) Fused silica ablation in $\operatorname{Ar}[1.4(\boldsymbol{\Delta}), 0.93(\mathbf{\square})$, and 0.59 $\mathrm{cm} / \mu \mathrm{s}(\bullet)$. (b) Fused silica ablation in $\mathrm{N}_{2}$ at various pressures and charging voltages of 16 and $18 \mathrm{kV}(1.0(\bigcirc), 0.80(\mathbf{\square}), 0.41(\diamond)$, and $0.38 \mathrm{~cm} / \mu \mathrm{s}$ $(\triangle)]$.

spark charging voltage, was varied. For a charging voltage of $16 \mathrm{kV}$, Fig. 4(b) shows that the expansion velocity ranges from 0.41 to $0.80 \mathrm{~cm} / \mu \mathrm{s}$. At $18 \mathrm{kV}$, the expansion velocity ranges from 0.38 to $1.0 \mathrm{~cm} / \mu$ s. It is apparent from Fig. 4 that
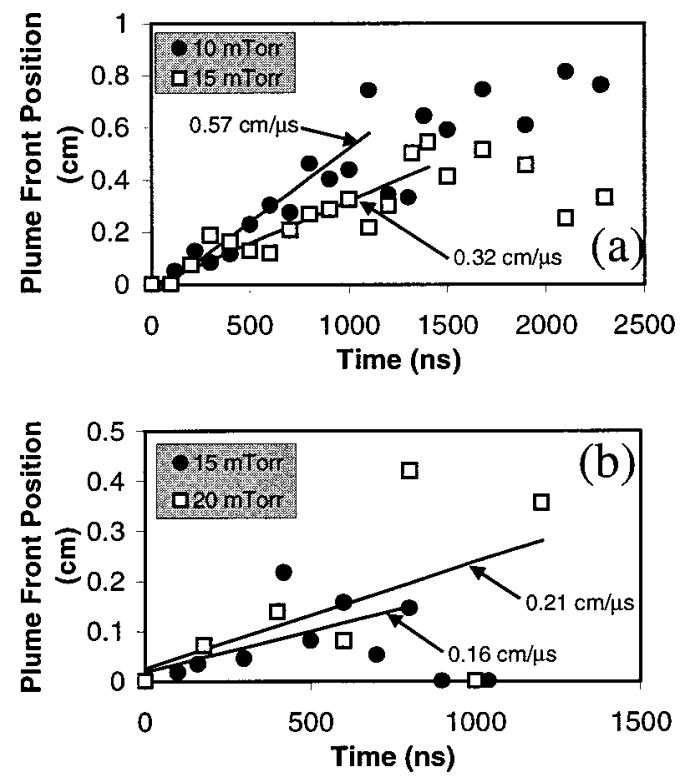

FIG. 5. Plot of Si I near-ground-state plume front position vs time following the electron beam pulse in an $\mathrm{Ar}$ or $\mathrm{N}_{2}$ background at various pressures. Data taken from DLRAP photographs of channelspark ablation of silicon. The dye laser was tuned to the center of the Si I transition at $288.1579 \mathrm{~nm}$. The initial time plume front data were fit by the method of least squares to determine an expansion velocity. The fit lines are also plotted along with their slopes. (a) $\mathrm{Si}$ ablation in $\operatorname{Ar}[0.57(\bullet)$ and $0.32 \mathrm{~cm} / \mu \mathrm{s}(\square)]$. (b) $\mathrm{Si}$ ablation in $\mathrm{N}_{2}[0.21(\square)$ and $0.16 \mathrm{~cm} / \mu \mathrm{s}(\bullet)]$.

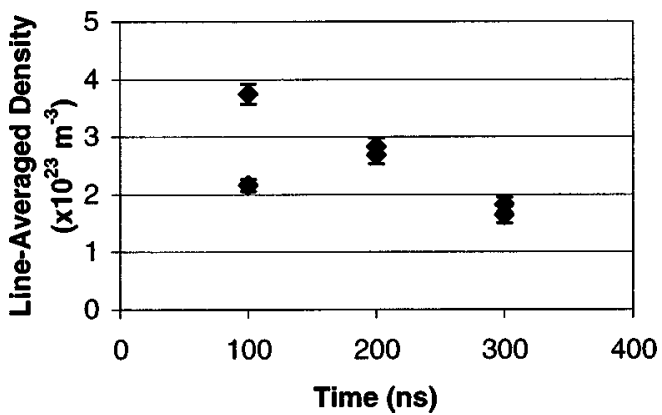

FIG. 6. Plot of the line-average electron density in electron beam ablation plumes vs time. Times are measured relative to the leading edge of the electron beam current pulse. Fused silica was ablated by the channel spark electron beam in a background of $19 \mathrm{mTorr}$ of $\mathrm{N}_{2}$. Line-integrated densities were measured by interferometry and a scale length of $3 \mathrm{~mm}$ was applied to determine the density.

the charging voltage has a minor effect upon the expansion velocity of electron beam ablated plumes. Increasing background gas pressure, however, causes the expansion velocity of neutral silicon plumes generated by e-beam ablation of fused silica to rise.

Figure 5(a) shows the expansion velocity of neutral $\mathrm{Si}$ plumes generated by e-beam ablation of $\mathrm{Si}$ in Ar background, which drops from 0.57 to $0.32 \mathrm{~cm} / \mu$ s for a rise in background pressure of 10-15 mTorr. Also observed in Fig. 5(b), the expansion velocity of Si neutral plumes formed by electron beam ablation of $\mathrm{Si}$ is much lower for $\mathrm{N}_{2}$ background. The plume front position is also quite erratic over time. Apparently the electron beam effective fluence is marginal for ablating $\mathrm{Si}$ in $\mathrm{N}_{2}$. The slower plume expansion velocities are a direct result of lower effective fluence at any position on the target due to the electron beam instability.

The plume expansion velocity in background gas fills of Ar is consistently $0.1-0.6 \mathrm{~cm} / \mu$ s larger than those for $\mathrm{N}_{2}$, for electron beam ablation of either fused silica or silicon. As mentioned before, the charging voltage has little effect on expansion velocity. Data reported by Gilgenbach and Ventzek $^{33}$ and Gilgenbach and Lindley ${ }^{5}$ show KrF laser ablated plumes of neutral $\mathrm{Al}$ that have similar expansion velocities at laser fluences ranging from 1.5 to $3 \mathrm{~J} / \mathrm{cm}^{2}$. In addition, they report rising expansion velocities with respect to rising fluence. In light of this information, it can be assumed that Ar results in a higher effective electron beam fluence than $\mathrm{N}_{2}$, probably due to differences in the formation of the ion channel. In addition, larger background pressures result in faster expansion velocities, as might be expected if the beam is better space charge neutralized. The drop in expansion velocity with increasing background Ar pressure during e-beam ablation of Si might indicate a dependence of the electron beam instability on neutralizing fraction.

\section{Interferometry}

The method of nonresonant interferometry was employed to measure line-averaged electron densities as presented in Fig. 6. Interferograms were taken, at a dye laser tuning of $540 \mathrm{~nm}$, during electron beam ablation of fused silica in 19 mTorr of $\mathrm{N}_{2}$. Fringe shifting only occurred on 

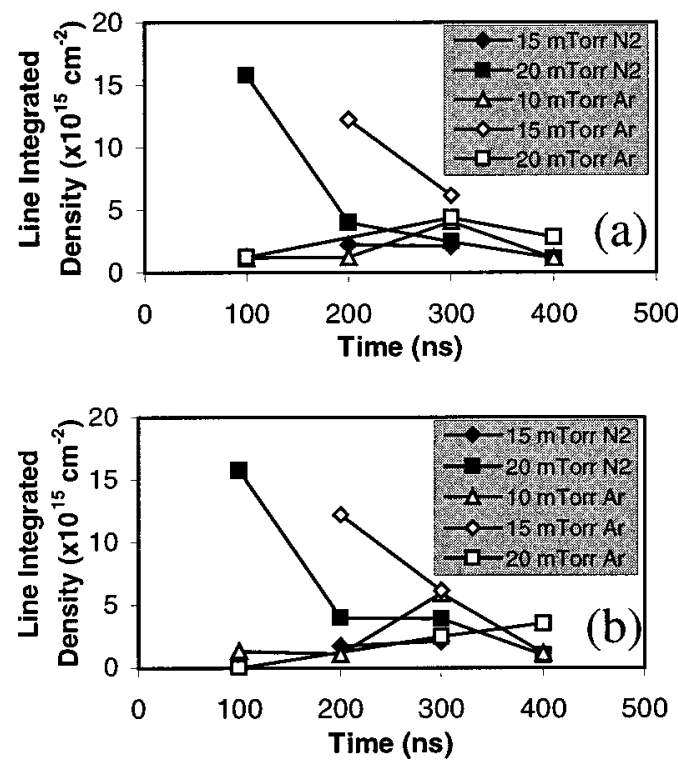

FIG. 7. Maximum line-integrated density of Si I near ground state atoms at (a) 0.4 and (b) $0.7 \mathrm{~mm}$ in front of the fused silica electron beam target. Data for several pressures of $\mathrm{Ar}$ or $\mathrm{N}_{2}$ background gas fill are included. Times are measured relative to the leading edge of the electron beam current pulse.

the fringe nearest the target, so only the maximum fringe shift was measured. The maximum fringe shift was found about $0.5 \mathrm{~mm}$ in front of the target surface, along the target normal. Interferometry yields line-integrated densities, so a scale length of $3 \mathrm{~mm}$, derived from the interferograms themselves, was used to calculate the line-averaged electron density. The line-averaged electron density has values ranging from 3.7 to $1.6 \times 10^{23} \mathrm{~m}^{-3}$. Table II lists published electron densities measured during laser ablation of various targets. From Table II and the data presented here, it is clear that channel spark electron beam ablation produces similar, if not somewhat smaller peak electron densities than laser ablation.

Resonant ultraviolet interferometry (RUVI) was used to probe the density of $\mathrm{Si}$ near ground state neutrals produced during electron beam ablation of fused silica. The theory of resonant fringe shift interpretation has been studied extensively and reported previously, ${ }^{5}$ therefore it will not be revisited here. For these experiments the dye laser was tuned near the Si I near ground state transition at $288.1579 \mathrm{~nm}$ $\left(\Delta \lambda=\lambda-\lambda_{o}=-0.2\right.$ or $-0.25 \mathrm{~nm}$, where $\left.\lambda_{o}=288.158 \mathrm{~nm}\right)$. The fringe shifts were corrected for electron density using the data from nonresonant interferometry, thus the measured and corrected shift was expected to be due to the near ground state Si neutrals only. Ablation experiments were studied at several pressures of either Ar or $\mathrm{N}_{2}$ background fill gas.

Figure 7 shows maximum line integrated densities measured of Si neutral atoms at 0.4 and $0.7 \mathrm{~mm}$ in front of the electron beam ablation target for several pressures of either Ar or $\mathrm{N}_{2}$ background fill gas. The ablations in 15 mTorr of Ar and 20 mTorr of $\mathrm{N}_{2}$ provided the largest line integrated $\mathrm{Si}$ densities, with most cases yielding line integrated densities between 1 and $16 \times 10^{15} \mathrm{~cm}^{-2}$. Table II contains a listing of published line integrated densities measured during laser ablation. Examining Table II and comparing it to the results of this work shows that at early times and very near the target, the channelspark produces silicon plasmas that are an order of magnitude more dense than laser ablation metal plasmas. It should be mentioned that each of the references cited in Table II measured plasma densities as late as 1 or $2 \mu$ s after the laser pulse. The channelspark plasmas fell below the detectability limit for Si I by 400 ns after the initial $10 \%$ of the electron beam current rise.

Assuming a triangular density profile along the fringe direction and a stepwise density profile along the target normal, the line integrated densities could be integrated over the plane of the image to arrive at a total number of resonant $\mathrm{Si}$ atoms versus time. The total number of resonant neutral $\mathrm{Si}$ atoms was calculated in this manner to be on the order of $10^{14}$. For electron temperatures of $1.1-1.2 \mathrm{eV}$, the total number of neutral $\mathrm{Si}$ atoms can be estimated to be about 5 times the total number of resonant neutral $\mathrm{Si}$ atoms, assuming a Boltzmann distribution among the atomic states. The total number of Si neutral atoms, assuming a Boltzmann distribution, and averaged over all the different pressure cases, was calculated to be $3.5 \times 10^{14}$ and $1.5 \times 10^{14}$ for 300 and $400 \mathrm{~ns}$, respectively. Note that some unknown fraction of these $\mathrm{Si}$ neutrals can be expected to deposit on the substrate, depending upon the unknown sticking coefficient and transport efficiency. Using the data from time resolved monochromator spectroscopy of fused silica ablation, the ratio of Si II to Si I atoms can be determined from the ratio of their emission intensities. Performing such an analysis, the Si II population can be expected to be 130 to 140 times the population of Si I resonant to $288.1579 \mathrm{~nm}$ light. The total number of singly charged silicon ions can be estimated at $4.6 \times 10^{16}$ and 2.1 $\times 10^{16}$ at 300 and $400 \mathrm{~ns}$, respectively. Lindley found the total number of ground state $\mathrm{Al}$ neutrals generated by $\mathrm{KrF}$ laser ablation of $\mathrm{Al}$ metal during a film deposition to be $0.3 \times 10^{14}$ at $0.6-1.2 \mu$ s after the laser pulse. ${ }^{5}$ This result is about a factor of ten smaller than the estimates for the channelspark, but only accounts for the ground state and is quoted at much later times than the channelspark data. Lash reports the total number of neutral iron atoms generated by $\mathrm{KrF}$ laser ablation to be $2-3 \times 10^{14}$ at $400 \mathrm{~ns}$ after the laser pulse, ${ }^{4}$ which corresponds very well to channelspark results. Lash also measured the total number of singly ionized Fe generated by $\mathrm{KrF}$ laser ablation to be between 2 and $4 \times 10^{15}$ at $400 \mathrm{~ns}$ after the laser pulse. This result is a factor of 10 smaller than estimates for the total number of ions generated by channelspark electron beam ablation of fused silica. It should be noted, however, that Lash measured those ion densities directly, through interferometry, which was not possible for these electron beam ablation experiments.

The total mass of $\mathrm{Si}$ atoms and ions existing at $400 \mathrm{~ns}$ can be found from the estimates of the total number of particles ablated by the channelspark electron beam. The channel spark is thereby found to ablate about $1 \mu \mathrm{g}$ of $\mathrm{Si}$ in the form of neutral atoms and ions.

\section{Thin film deposition}

Thin films of $\mathrm{SiO}_{2}$ were deposited on silicon or copper substrates by electron beam ablation of fused silica. Figure 8 is a scanning electron microscope image of a cleaved silicon dioxide film on a silicon substrate, magnified $10000 \times$. The 


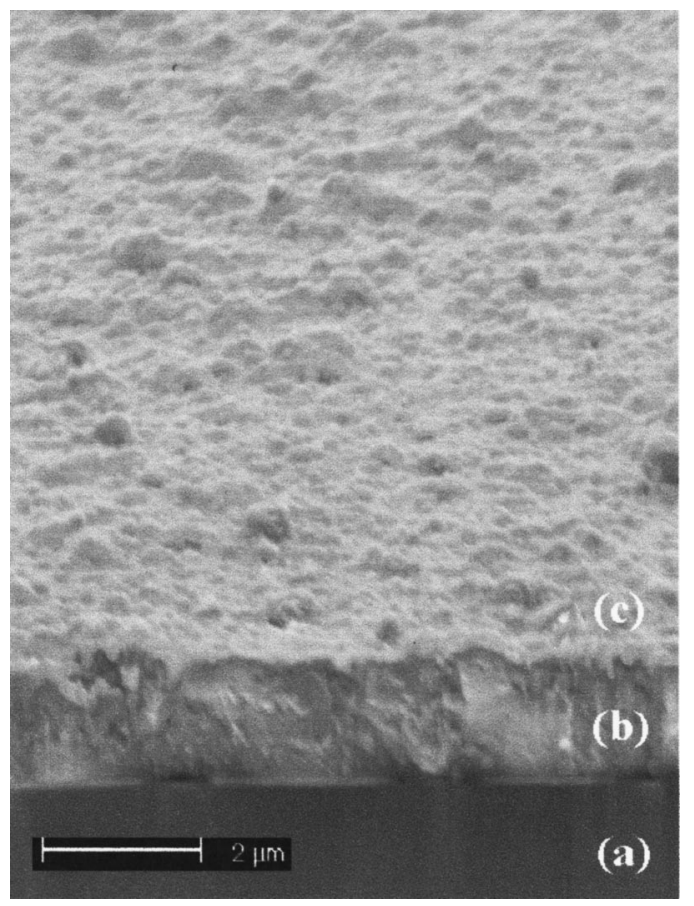

FIG. 8. Scanning electron microscopy (SEM) image of a fused silica film deposited on a silicon substrate. Image shows a cleaved film and substrate. Substrate normal is $75^{\circ}$ from the direction of viewing. SEM electron beam voltage was $3.00 \mathrm{kV}$. Magnification was $10000 \times$. Film was deposited in 2400 shots at $1 \mathrm{~Hz}$. (a) Si substrate. (b) Cross-section of the fused silica film. (c) Surface of the film.

film has been cleaved through its thickest point, and is positioned in the photograph with the target normal pointing $75^{\circ}$ from the direction of viewing. The film itself was deposited over 2400 shots at a $1 \mathrm{~Hz}$ repetition rate. The channel spark was charged to $16.5 \mathrm{kV}$ and operated in a background of 15 mTorr of Ar. The surface of the film is observed to be quite rough, seemingly composed of large, coagulated particles. The interior of the film appears to be quite continuous and solid, with few voids. The film thickness was found to be $1.58 \pm 0.11 \mu \mathrm{m}$. To one standard deviation, the film thickness varies by $7 \%$. This thickness yields an average deposition rate of $0.66 \mathrm{~nm} / \mathrm{shot}$.

The stoichiometry of the channelspark deposited silicon dioxide films was examined through x-ray energy dispersive spectroscopy (XEDS). The film examined was deposited in 3000 ablation shots of fused silica at $1 \mathrm{~Hz}$ repetition rate onto a $\mathrm{Cu}$ substrate. The $\mathrm{Cu}$ substrate was chosen to eliminate ambiguity regarding the origin of the Si X-ray signal. A piece of the fused silica target used for the deposition was also studied to provide a calibration standard for the stoichiometry. The results of the analysis are presented in Table III,

TABLE III. List of atomic percentages and parameters of XEDS analysis of channel spark electron beam fused silica target and film.

\begin{tabular}{lcc}
\hline \multicolumn{1}{c}{ Sample } & Atomic \%O & Atomic \% Si \\
\hline Fused silica target & 67.68 & 32.32 \\
Fused silica film on Cu-spot 1 & 69.18 & 30.82 \\
Fused silica film on Cu-spot 2 & 68.02 & 31.98 \\
\hline \hline
\end{tabular}

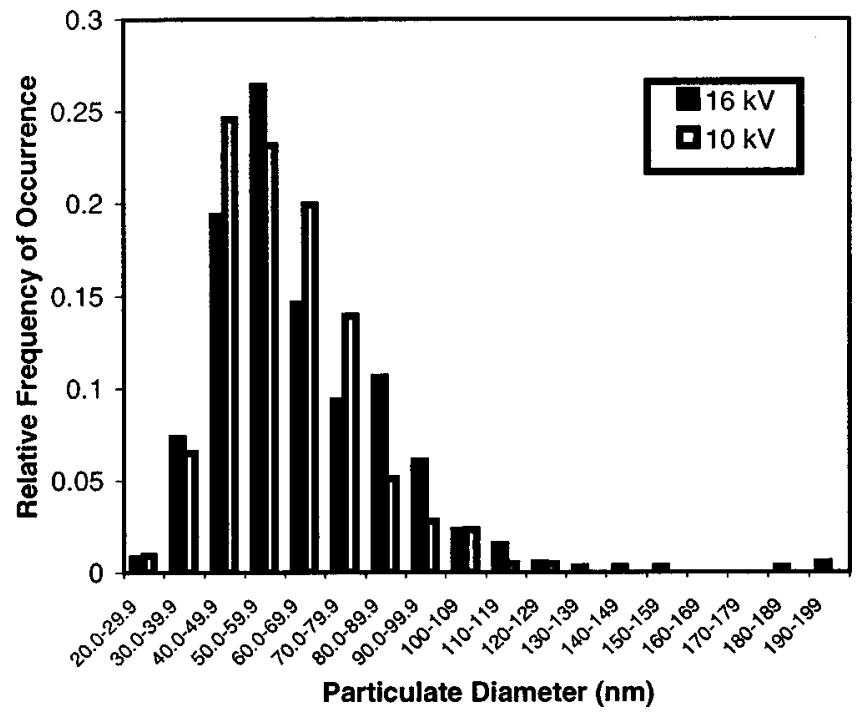

FIG. 9. Histogram of the relative occurrence of particle diameters in channel spark electron beam deposited films of fused silica. Films deposited with channelspark charging voltages of 10 and $16 \mathrm{kV}$ are included. The bin widths are $10 \mathrm{~nm}$.

which presents atomic percentages of $\mathrm{Si}$ and $\mathrm{O}$ from the target and two positions on the same film. The stoichiometry is observed to be accurately preserved in the film compared to the fused silica target, an advantageous result for the channelspark electron beam ablation system.

Since the films appear to contain particulate, the production of particulate by the channelspark electron beam was also studied. Films with very few shots, ranging from 60 to 300 , were deposited to examine the isolated particulate, before a very thick film could be formed. The isolated particles would then represent the source particulate distribution produced by electron beam ablation. Figure 9 is a histogram plot of the relative distribution of particulate diameters for two channelspark charging voltages, 10 and $16 \mathrm{kV}$. These particulate depositions were performed in a background of 15 mTorr of Ar. The lower voltage deposition was performed in an attempt to reduce the diameter of the particulate produced by electron beam ablation by reducing the electron range in the target and therefore reducing the melt depth. For the 16 $\mathrm{kV}$ deposition, the mean particle diameter was $64 \mathrm{~nm}$ with a most frequently observed diameter between 50 and $60 \mathrm{~nm}$. The sampled population included 398 particles covering an area of $96.7 \mu \mathrm{m}^{2}$. The $10 \mathrm{kV}$ deposition resulted in a mean particle diameter of $60 \mathrm{~nm}$ with a most frequently observed diameter between 40 and $50 \mathrm{~nm}$. The sampled population in this case included 216 particles covering a $4.4 \mu \mathrm{m}^{2}$ area. The lowered voltage did result in smaller average diameter particles, but only slightly smaller. Smaller droplets would be expected from a shallower melt depth.

An attempt was made to determine the mass of material deposited on the film, per shot, in the form of particulate. The distributions discussed above were examined near the center of the film, the densest $\left(\mathrm{No} . / \mathrm{cm}^{2}\right)$ region of the film. Assuming a cosine shaped film with cylindrical symmetry, the data presented in the preceding paragraph could be integrated over the surface of the film to calculate the total vol- 
ume of particulate deposited. Assuming a density equal to that of fused silica, $2.21 \mathrm{~g} / \mathrm{cm}^{3}$, the total mass in the form of particulate could be calculated. For the $10 \mathrm{kV}$ deposition, the mass of deposited particulate per shot was estimated to be about $10 \mathrm{ng} / \mathrm{shot}$. For the $16 \mathrm{kV}$ deposition, the deposited particulate mass was estimated to be $7 \mathrm{ng} / \mathrm{shot}$. Using a similar analysis of the film shown in Fig. 8 (namely assuming a cosine shaped film whose maximum thickness is $1.6 \mu \mathrm{m}$ over 2400 shots and using the density of fused silica), a total mass of the film deposited per shot could be calculated. This mass was estimated to be $350 \mathrm{ng} / \mathrm{shot}$. Thus, the particulate compose $2 \%-3 \%$ of the total deposited film mass.

\section{SUMMARY AND CONCLUSIONS}

Electron beam ablation has been studied extensively by nonperturbing plasma diagnostics such as optical emission spectroscopy, dye laser resonance absorption photography (DLRAP), nonresonant interferometry, and resonant ultraviolet interferometry (RUVI). The relative emission intensities of singly ionized titanium transitions in electron beam ablated plumes of TiN showed a free electron temperature of $1.1 \mathrm{eV}$. The ratio of emission intensity from transitions of $\mathrm{Si}$ II and Si I showed a free electron temperature of $1.2 \mathrm{eV}$, in close agreement with the results from TiN ablation. Dye laser resonance absorption photography has yielded strong indications of an electron beam instability, which is dependent upon the conductivity of the target, during electron beam ablation. Si atom plume expansion velocities of $0.38-1.4$ $\mathrm{cm} / \mu$ s during ablation of fused silica have been found through the analysis of DLRAP images. These expansion velocities correspond quite well to those of laser ablation plumes. ${ }^{5,33}$ The expansion velocity was found to rise with increasing background pressure, but to be relatively unaffected by charging voltage. The expansion velocity of plumes generated during $\mathrm{Si}$ ablation, ranging from 0.16 to $0.57 \mathrm{~cm} / \mu \mathrm{s}$, were observed to be slower than those for fused silica ablation. These lower expansion velocities are probably attributable to the higher thermal conductivity of Si and to a lower effective fluence delivered to the target due to the electron beam instability. Nonresonant interferometry yielded electron densities ranging from nearly $4 \times 10^{23} \mathrm{~m}^{-3}$ at $100 \mathrm{~ns}$ to $1.5 \times 10^{23} \mathrm{~m}^{-3}$ at $300 \mathrm{~ns}$ after $\tau_{10}$. Resonant ultraviolet interferometry during electron beam ablation of fused silica found line-integrated $\mathrm{Si}$ atom densities from 1 to $16 \times 10^{15} \mathrm{~cm}^{-2}$, for various pressures of either $\operatorname{Ar}$ or $\mathrm{N}_{2}$, out to $0.7 \mathrm{~mm}$ in front of the target, at $100-400 \mathrm{~ns}$ after $\tau_{10}$. From these results, assuming a free electron temperature of $1.2 \mathrm{eV}$, the total number of neutral $\mathrm{Si}$ atoms was estimated to be $1.5 \times 10^{14}$ at $400 \mathrm{~ns}$. The total number of singly charged $\mathrm{Si}$ ions was estimated to be 2.1 $\times 10^{16}$ at $400 \mathrm{~ns}$. These values correspond to an ablated mass of about $1 \mu \mathrm{g}$ per shot.

Films deposited by electron beam ablation of fused silica were examined by scanning electron microscope and $\mathrm{x}$-ray energy dispersive spectroscopy (XEDS). The surface of these films was observed to be quite rough, with a thickness variation of $7 \%$ for a film deposited on Si over 2400 shots. This film's thickness was measured to be $1.58 \mu \mathrm{m}$, yielding a deposition rate of $0.66 \mathrm{~nm} / \mathrm{shot}$. XEDS analysis found that the film stoichiometry matched the target to within a few percent. Analysis of the particulate deposited on the substrate showed that the mean particulate diameter ablated by the channelspark was $64 \mathrm{~nm}$ at $16 \mathrm{kV}$ charging voltage, and 60 $\mathrm{nm}$ at $10 \mathrm{kV}$ charging voltage. The mass of ablated particulate per shot was estimated to be about $10 \mathrm{ng} / \mathrm{shot}$. The mass deposition rate of the film as a whole was estimated to be about $350 \mathrm{ng} / \mathrm{shot}$. Thus, particulate accounts for about $3 \%$ of the total film mass. It would appear that electron beam ablated $\mathrm{SiO}_{2}$ plumes are deposited predominately in the form of atomized/ ionized material, with only a few percent of the deposited mass being accounted for by particulate. This result is corroborated by the ablated mass of Si calculated from RUVI data of $1 \mu \mathrm{g} / \mathrm{shot}$. This result takes no account of transport efficiency after $400 \mathrm{~ns}$ nor of the sticking coefficient at the substrate, but does show that electron beam ablation is relatively efficient $(\sim 30 \%)$ at generating atomized/ ionized material for deposition.

\section{ACKNOWLEDGMENTS}

This work was supported by National Science Foundation Grant No. CTS-9522282. We appreciate fruitful discussions with David Hinshelwood.

${ }^{1}$ R. P. van Ingen, J. Appl. Phys. 76, 8055 (1994).

${ }^{2}$ J. Hermann, C. Boulmer-Leborgne, and D. Hong, J. Appl. Phys. 83, 691 (1998).

${ }^{3}$ X. T. Wang, B. Y. Man, G. T. Wang, Z. Zhao, Y. Liao, B. Z. Xu, Y. Y. Xia, L. M. Mei, and X. Y. Hu, J. Appl. Phys. 80, 1783 (1996).

${ }^{4}$ J. S. Lash, R. M. Gilgenbach, and H. L. Spindler, J. Appl. Phys. 79, 2287 (1996).

${ }^{5}$ R. A. Lindley, R. M. Gilgenbach, C. H. Ching, J. S. Lash, and G. L. Doll, J. Appl. Phys. 76, 5457 (1994).

${ }^{6}$ J. M. Gonzalez, M. I. Montero, L. Vazquez, J. A. Martin Gago, D. Givord, C. de Julian, and K. O'Grady, IEEE Trans. J. Magn. Jpn. 34, 1108 (1998).

${ }^{7}$ S. Keitoku and H. Ezumi, IEEE Trans. J. Magn. Jpn. 7, 858 (1992).

${ }^{8}$ P. R. Wilmott, R. Timm, and J. R. Huber, J. Appl. Phys. 82, 2082 (1997).

${ }^{9}$ E. N. Glezer and E. Mazu, Appl. Phys. Lett. 71, 882 (1997).

${ }^{10}$ J. Ihlemann, Appl. Surf. Sci. 54, 193 (1992).

${ }^{11}$ K. Sugioka, S. Wada, H. Tashiro, K. Toyoda, and A. Nakamura, Appl. Phys. Lett. 65, 1510 (1994).

${ }^{12}$ T. P. Chen, T.-I. Bao, and I. Lin, Appl. Phys. Lett. 63, 2475 (1993).

${ }^{13}$ J. T. Dickinson, S. C. Langford, L. C. Jensen, P. A. Eschbach, L. R. Pederson, and D. R. Baer, J. Appl. Phys. 68, 1831 (1990).

${ }^{14}$ Z. Ren, Y. Du, Y. Qiu, J. Wu, Z. Ying, X. Xiong, and F. Li, Phys. Rev. B 51, 5274 (1995).

${ }^{15}$ J. Christiansen and C. Schultheiss, Z. Phys. A 290, 35 (1979).

${ }^{16}$ W. Benker, J. Christiansen, K. Frank, H. Gundel, W. Hartmann, T. Redel, and M. Stetter, IEEE Trans. Plasma Sci. 17, 754 (1989).

${ }^{17}$ R. Stark, J. Christiansen, K. Frank, F. Mucke, and M. Stetter, IEEE Trans. Plasma Sci. 23, 258 (1995)

${ }^{18}$ S. Christiansen, F. Mucke, J. Markl, W. Dorsch, R. Stark, K. Frank, H. P. Strunk, G. Saemann-Ischenko, and J. Christiansen, J. Cryst. Growth 166, 848 (1996).

${ }^{19}$ G. Muller and C. Schultheiss, Proceedings of 10th International Conference On High Power Particle Beams, San Diego, 20-24 June 1994 (unpublished), Vol. 2, p. 833.

${ }^{20}$ Q. D. Jiang, F. C. Matacotta, M. C. Konijnenberg, G. Muller, and C. Schultheiss, Thin Solid Films 241, 100 (1994).

${ }^{21}$ Th. Witke, A. Lenk, B. Schultrich, and C. Schultheiss, Surf. Coat. Technol. 74, 580 (1995).

${ }^{22}$ S. D. Kovaleski, R. M. Gilgenbach, L. K. Ang, Y. Y. Lau, and J. S. Lash, Appl. Surf. Sci. 127-129, 947 (1998). 
${ }^{23}$ S. D. Kovaleski, R. M. Gilgenbach, L. K. Ang, and Y. Y. Lau, Appl. Phys. Lett. 73, 2576 (1998).

${ }^{24}$ R. M. Gilgenbach, S. D. Kovaleski, J. S. Lash, L. K. Ang, and Y. Y. Lau, IEEE Trans. Plasma Sci. 27, 150 (1999).

${ }^{25}$ H.R. Griem, Principles of Plasma Spectroscopy (Cambridge University Press, Cambridge, 1997).

${ }^{26}$ R. Jayakumar and H. H. Fleischmann, J. Quant. Spectrosc. Radiat. Transf. 33, 177 (1985).

${ }^{27}$ M. L. Brake and T. E. Repetti, IEEE Trans. Plasma Sci. 17, 60 (1989).

${ }^{28}$ NIST Atomic Spectra Database, March 22, 1999, National Institute of Standards and Technology, March 31, 1999, 〈http://physics.nist.gov/cgibin/AtData/main_asd $>$.
${ }^{29}$ J. Hermann, C. Vivien, A. P. Carricato, and C. Boulmer-Leborgne, Appl. Surf. Sci. 127-129, 645 (1998).

${ }^{30}$ R. M. Gilgenbach, C. H. Ching, J. S. Lash, and R. A. Lindley, Phys. Plasmas 1, 1619 (1994).

${ }^{31}$ L. A. Doyle, G. W. Martin, A. Al-Khateeb, I. Weaver, D. Riley, M. J. Lamb, T. Morrow, and C. L. S. Lewis, Appl. Surf. Sci. 127-129, 716 (1998).

${ }^{32}$ G. W. Martin, L. A. Doyle, A. Al-Khateeb, I. Weaver, D. Riley, M. J. Lamb, T. Morrow, and C. L. S. Lewis, Appl. Surf. Sci. 127-129, 710 (1998).

${ }^{33}$ R. M. Gilgenbach and P. L. G. Ventzek, Appl. Phys. Lett. 58, 1597 (1991). 